\title{
Point-of-care testing for HIV
}

\author{
Daniel Dalcin MD, Isaac I. Bogoch MD MS
}

Cite as: CMAJ 2018 May 7;190:E569. doi: 10.1503/cmaj.180068

\section{Point-of-care testing for HIV provides results \\ in minutes}

Point-of-care testing for HIV, in which finger-prick blood or saliva samples are analyzed, provides preliminary results at the same patient encounter that testing is performed. It is useful in settings where patients may have challenges attending subsequent appointments or when a rapid HIV diagnosis would change clinical management. Point-of-care HIV tests are used worldwide and were first approved by Health Canada in 2005. ${ }^{1}$

2

\section{Point-of-care HIV tests licensed for clinical use in Canada have high sensitivity and specificity} Point-of-care HIV tests have variable sensitivities and specificities depending on the individual assay. For example, the test licensed for use in British Columbia has a sensitivity and specificity of $99.6 \%$ (95\% confidence interval $[\mathrm{Cl}]$ 98.9\%-99.9\%) and $99.7 \%$ (95\% Cl 99.4\%-99.8\%), respectively. Point-ofcare HIV tests are less sensitive than laboratory-based testing for detecting acute HIV infection. ${ }^{2}$

\section{3}

\section{Point-of-care testing for HIV should be followed by laboratory- based testing}

Depending on the result of the point-of-care HIV test, further laboratory testing may be required (Box 1).3,4

\section{4}

Point-of-care testing increases rates of HIV testing among those at high risk for HIV infection

A recent meta-analysis found that point-of-care testing for HIV was associated with increased rates of testing for HIV and delivery of HIV status results to patients, compared to conventional laboratory-based HIV testing. ${ }^{3}$

\section{Clinicians should consider the unique aspects of point-of-care testing for HIV before implementation}

Requirements for pre- and posttest counselling, linkage to HIV care (when appropriate) mandatory reporting to public health, as well as documentation and follow-up of preliminary results, vary depending on country, state or province and institution of practice, and should be considered before performing point-of-care testing for HIV. ${ }^{5}$

\section{References}

1. Minichiello A, Swab M, Chongo M, et al. HIV point-of-care testing in Canadian settings: a scoping review. Front Public Health 2017;5:76.

2. Communicable Disease Control Manual - Chapter 5: Point of care HIV test guidelines for health care settings. Vancouver: BC Centre for Disease Control; 2014. Available: www.bccdc.ca/ resource-gallery/Documents/Communicable-Disease-Manual /Chapter\%205\%20-\%20STI/Point_of_Care_HIV_Test_Guidelines _for_HealthCareSettings_May2014.pdf (accessed 2018 Feb. 3).

3. Pottie K, Medu O, Welch V, et al. Effect of rapid HIV testing on $\mathrm{HIV}$ incidence and services in populations at high risk for HIV exposure: an equity-focused systematic review. BMJ Open 2014;4:e006859.

4. Point-of-care HIV testing using rapid HIV test kits: guidance for health-care professionals. CCDR 33S2:1-22. Ottawa: Public Health Agency of Canada; 2007. Available: www.phac-aspc.gc.ca /publicat/ccdr-rmtc/07pdf/33s2-eng.pdf (accessed 2018 Feb. 3).

5. Johnston B, Conly J. Point-of-care testing for HIV: HIV counselling and testing. Can J Infect Dis 2002;13:85-8.

\section{Competing interests: None declared.}

This article has been peer reviewed.

Affiliations: Department of Medicine (Dalcin), University of Calgary, Calgary, Alta; Department of Medicine (Bogoch), University of Toronto; Divisions of General Internal Medicine and Infectious Diseases (Bogoch), University Health Network, Toronto, Ont.

Correspondence to: Isaac Bogoch, isaac.bogoch@ uhn.ca 